\title{
PON3 is upregulated in cancer tissues and protects against mitochondrial superoxide-mediated cell death
}

\author{
E-M Schweikert ${ }^{1,6}$, A Devarajan ${ }^{2,6}$, I Witte ${ }^{1}$, P Wilgenbus ${ }^{1}$, J Amort ${ }^{1}$, U Förstermann ${ }^{1}$, A Shabazian², V Grijalva ${ }^{2}$, DM Shih ${ }^{2}$, \\ R Farias-Eisner ${ }^{3}$, JF Teiber ${ }^{4}$, ST Reddy ${ }^{2,3,5,7}$ and S Horke ${ }^{\star, 1,7}$
}

To achieve malignancy, cancer cells convert numerous signaling pathways, with evasion from cell death being a characteristic hallmark. The cell death machinery represents an anti-cancer target demanding constant identification of tumor-specific signaling molecules. Control of mitochondrial radical formation, particularly superoxide interconnects cell death signals with appropriate mechanistic execution. Superoxide is potentially damaging, but also triggers mitochondrial cytochrome $c$ release. While paraoxonase (PON) enzymes are known to protect against cardiovascular diseases, recent data revealed that PON2 attenuated mitochondrial radical formation and execution of cell death. Another family member, PON3, is poorly investigated. Using various cell culture systems and knockout mice, here we addressed its potential role in cancer. PON3 is found overexpressed in various human tumors and diminishes mitochondrial superoxide formation. It directly interacts with coenzyme Q10 and presumably acts by sequestering ubisemiquinone, leading to enhanced cell death resistance. Localized to the endoplasmic reticulum (ER) and mitochondria, PON3 abrogates apoptosis in response to DNA damage or intrinsic but not extrinsic stimulation. Moreover, PON3 impaired ER stress-induced apoptotic MAPK signaling and CHOP induction. Therefore, our study reveals the mechanism underlying PON3's anti-oxidative effect and demonstrates a previously unanticipated function in tumor cell development. We suggest PONs represent a novel class of enzymes crucially controlling mitochondrial radical generation and cell death.

Cell Death and Differentiation (2012) 19, 1549-1560; doi:10.1038/cdd.2012.35; published online 23 March 2012

Cancer is one of the most life-threatening diseases and will remain a demanding issue in healthcare given the increase in life expectancy, constantly growing population and incidence of risk-factor acquiring patients. It is well established that several cellular deregulations are required for durable malignant transformation. Among them are sustained proliferation, replicative immortality, evasion of immune destruction and escape from cell death. ${ }^{1}$ Thus, tumor cells represent complex, broadly re-organized entities such that effective therapies demand tumor-specific identification of underlying mechanisms to reveal 'weak points'. Combinations of multiple targeting strategies with moderate compound concentrations are more promising and provoke less side-effects than highdose single treatment. Moreover, besides targeting the machinery directly involved in cell death execution, the preceding signaling pathways are attractive targets as these harbor critical upstream mediators with many of them understudied. Generally, redox signaling at the mitochondria is a vital pathway relevant to this concept in cancer research, as it controls both energy metabolism and regulation of cell death. Therefore, it is not surprising that mitochondrial dysfunction relates to a plethora of diseases and that many lead compounds are currently being developed in order to manipulate this organelle. ${ }^{2}$ Importantly, via generation of reactive oxygen species (ROS) or $\mathrm{Ca}^{2+}$-triggered signaling events, mitochondria strongly impact on near-by and cancerrelated signaling such as the endoplasmic reticulum (ER) stress pathway as well as pro-inflammatory cytokine production. ${ }^{3}$ Thus, anti-oxidant molecules or proteins are promising targets in cancer therapy and the treatment of many other diseases.

The paraoxonase (PON) gene family consists of three genes, PON1, PON2 and PON3. All three PONs have antioxidant properties. Although human PONs have $60 \%$ similarity at the amino-acid level, their localization, stress response and functions (other than anti-oxidant function) are different. While PON1 is HDL associated, PON2 and PON3 are intracellular. In contrast to PON2, which is detected in various

\footnotetext{
${ }^{1}$ Department of Pharmacology, University Medical Center of the Johannes-Gutenberg University Mainz, Obere Zahlbacher Str. 67,55131 Mainz, Germany; ${ }^{2}$ Department of Medicine, University of California, Los Angeles, CA, USA; ${ }^{3}$ Department of Obstetrics and Gynecology, University of California, Los Angeles, CA 90095, USA; ${ }^{4}$ Department of Internal Medicine, Division of Epidemiology, University of Texas Southwestern Medical Center, 5323 Harry Hines Boulevard, Dallas, TX 75390, USA and ${ }^{5}$ Department of Molecular and Medical Pharmacology, University of California, Los Angeles, CA 90095, USA

*Corresponding author: S Horke, Department of Pharmacology, University Medical Center of the Johannes-Gutenberg University Mainz, Obere Zahlbacher Str. 67, 55131 Mainz, Germany. Tel: + 496131179196; Fax: + 496131179404; E-mail: horke@uni-mainz.de

${ }^{6}$ These authors contributed equally to this work.

${ }^{7}$ These authors shared last authorship.

Keywords: paraoxonase; apoptosis; endoplasmic reticulum stress; mitochondria; oxidative stress; cancer

Abbreviations: ALL, acute lymphoblastic leukemia; CHOP, C/EBP homologous protein; GADD153, growth arrest/DNA damage-inducible gene 153; CML, chronic myeloid leukemia; ER, endoplasmic reticulum; PON, paraoxonase; ROS, reactive oxygen species; SOD, superoxide dismutase; TNF- $\alpha$, tumor necrosis factor- $\alpha$; UPR, unfolded protein response

Received 16.9.11; revised 10.2.12; accepted 29.2.12; Edited by HU Simon; published online 23.3.12
} 
organs and presumably all types of cells, PON3 is absent in many cell types including macrophages, endothelial and smooth muscle cells. ${ }^{4}$ At the level of enzyme activity, PON1 hydrolyzes organophosphates, whereas PON2 and PON3 do practically not and it has been shown that the PONs have overlapping but also distinct activities. ${ }^{5,6}$ In contrast to PON1 and PON2, whose expression is regulated by ROS, PON3 message is not altered by oxidative stress. ${ }^{7,8}$ Despite these differences, studies in mice and humans suggest that all PONs protect against atherosclerosis, and seemingly also have a role in metabolic syndrome, HIV and neurodegenerative diseases. ${ }^{4,9,10}$ Importantly, it appears that the three members do not represent a simple backup system for each other, for example, since knocking out PON2 in mice promoted atherosclerosis and PON1 or PON3 appeared unable to compensate this loss. ${ }^{11}$ In addition, while the PONs can hydrolyze many of the same ester substrates, they also have very distinct enzymatic activities. For instance, hydrolysis of organophosphates is almost exclusive to PON1, while only PON3 can hydrolyze the cholesterol lowering statins. ${ }^{5}$ Collectively, while PON enzymes exhibit obvious similarities, several lines of evidence suggest a unique role for each enzyme that needs to be distinguished.

In the present study, we examined whether PON3 expression is regulated in cancer tissue/cell lines and whether PON3 participates in protection against mitochondrial oxidative stress and apoptosis. Our results demonstrate, for the first time, that PON3 is upregulated in various cancer tissues and localized to mitochondrial membranes. Further, this study reveals the anti-oxidative mechanism of PON3 and provides evidence that it protects against cell death. In light of recent findings with PON2, we postulate that PON2 and PON3 are important modulators of mitochondrial function and novel therapeutic targets for cancer biology.

\section{Results}

Expression of PON3 in cancer cells. Mitochondria are central to new concepts and drug development in cancer biology due to their critical function in energy metabolism and regulation of cell death. Previous studies linked the PON3 paralog PON2 to mitochondrial events and cell death. ${ }^{12-15}$ However, given the unique functions of PON3, its enigmatic anti-oxidative mechanism and role in certain pathophysiologies, we here addressed its redox-active mechanism and tested whether PON3 expression may be of relevance for tumor biology.

We investigated the expression of PON3 protein in a large panel of human cell lines. We found no PON3 expression in endothelial cells (HUVEC, EA.hy 926) and only low expression in chondrocyte C28I cells (Figure 1a). In contrast to PON2, PON3 expression appears to be largely restricted to cells derived from solid tumors, such as the lung (A549), liver (Huh7, HepG2) and colon (DLD-1, Caco-2) cancer cells. Recent studies demonstrated that PON2 increased chemoresistance in leukemic cells, ${ }^{15}$ was upregulated and associated with poor prognosis in cohorts of pediatric acute lymphoid leukemia $^{16,17}$ or with imatinib resistance in chronic myeloid leukemia $\left(\mathrm{CML}^{18}\right)$. Among the tested leukemia-like cell lines, PON3 is found only in CML-like $\mathrm{KCl}-\mathrm{R}$ and $\mathrm{KCl}-\mathrm{S}$ cells (resistant or sensitive to imatinib, respectively) (Figure 1b).

PON3 expression in the tumor environment. We next analyzed PON3 mRNA levels in $~ 380$ different samples obtained from normal and cancer tissues (Figure 2a). Except for cervix, PON3 was largely overexpressed. Reasonable overexpression appeared in tumors of ovary, kidney, lymphoid and colon ( 2-3-fold). High PON3 levels were found in tumors of pancreas, lung, urinary bladder, thyroid,

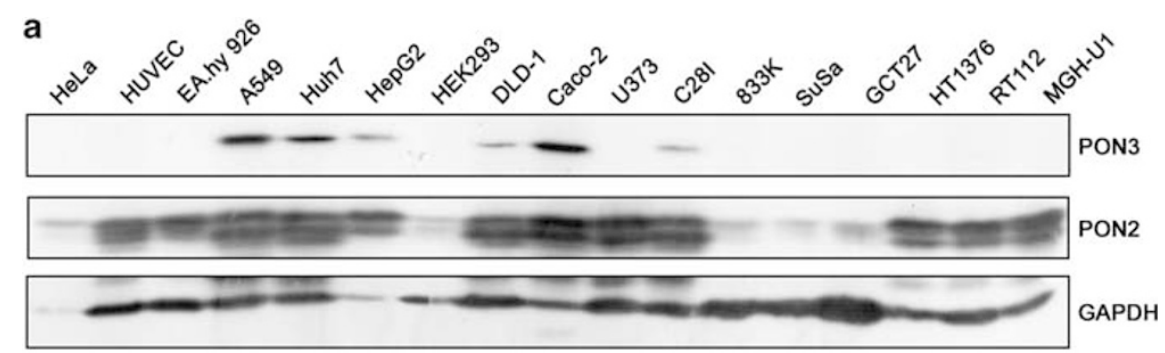

b

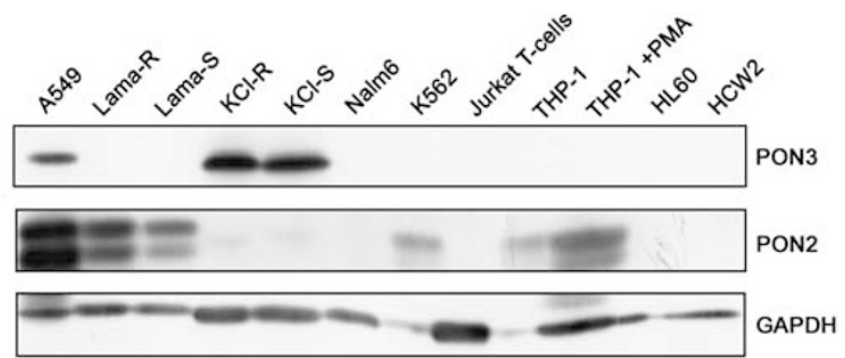

Figure 1 Characterization of PON3 protein expression in different cell lines or tumor cell lines derived from solid tumors (a) or leukemias (b). PON2 was blotted for comparison and GAPDH served as loading control. PON3 protein is mainly expressed in human lung, liver, colon and KCl (leukemia) tumor cell lines. For Lama and KCl cells, ' $R$ ' and ' $S$ ' indicate resistance or sensitivity to imatinib, respectively. THP-1 monocytes were differentiated into macrophages by PMA treatment ('THP-1 + PMA'). HUVEC, primary human umbilical vein endothelial cells 
a

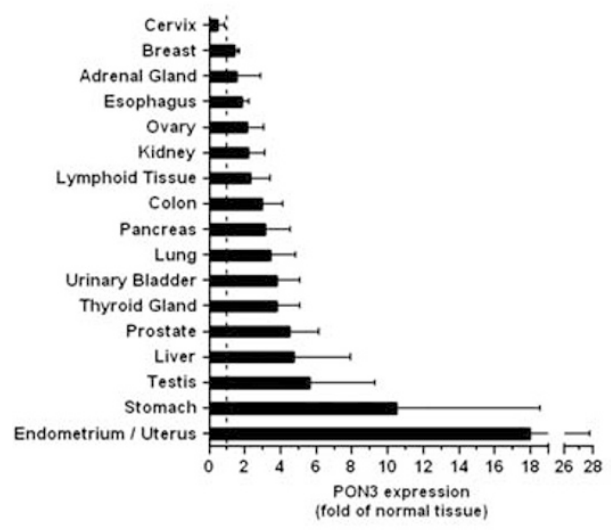

C

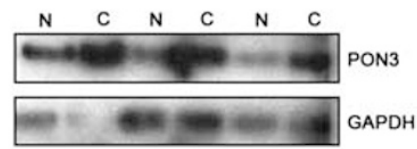

b
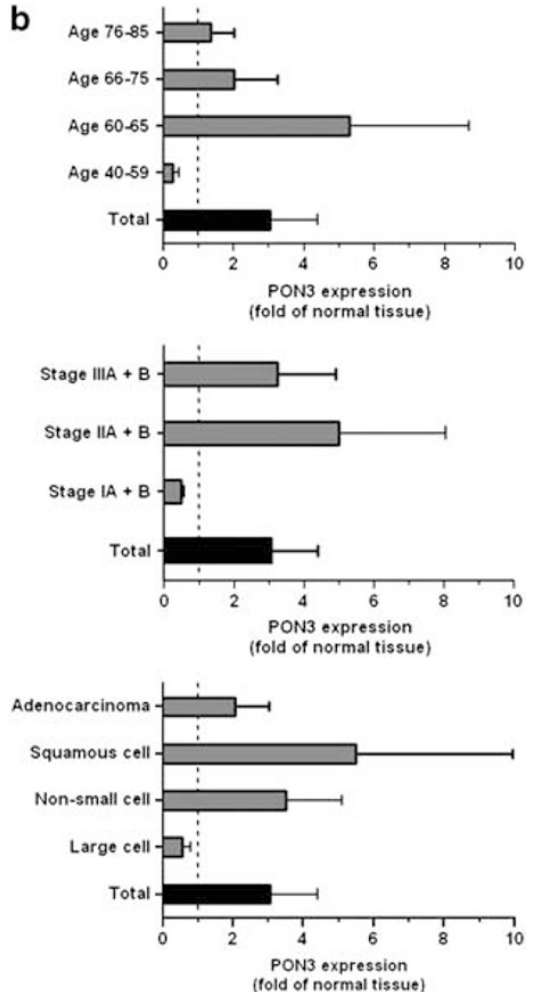

Figure 2 PON3 is found overexpressed in several human tumors. (a) PON3 CDNA expression levels were determined in cancer versus normal tissues by qRT-PCR using TissueScan cancer survey panels (covering $\sim 380 \mathrm{cDNA}$ samples from various tumors) and (b) lung cancer panels (covering 24 matched samples, that is, diseased and healthy tissue from the same patient). The 24 samples were either summarized ('total') or separated into different groups of age, stage or diagnosis. (c) PON3 protein is found upregulated in human ovarian cancer tissue. Western blot analysis of PON3 in protein extracts from three independent normal ovary tissue ('N') and ovarian carcinoma ('C'). GAPDH served as loading control

prostate, liver and testis (>3-fold). Strikingly, tumors from stomach and endometrium/uterus showed >10-fold upregulation of PON3. Matched lung cancer tissues with diseased and normal samples coming from the same patient revealed an overall threefold PON3 overexpression. Further classifications (Figure 2b) revealed that PON3 was upregulated in patients between the ages of 60-65, whereas younger patients (40-59 years) showed decreased PON3 level. PON3 expression was lowest in tumors at stage I, but enhanced at stages II and III. The highest increase of PON3 appeared in squamous cells. Also, the elevated PON3 cDNA levels found in ovarian cancers (Figure 2a) were confirmed by increased levels of PON3 protein when compared with matched normal tissues (Figure 2c).

Localization of PON3. Previous studies demonstrated an anti-oxidative effect of PON3, but underlying mechanisms remained unknown. Since protein effects depend on localization, we first examined PON3's subcellular distribution. Confocal microscopy of PON3-GFP in live HEK293 cells demonstrated that PON3 expression overlaps with markers of both mitochondria and ER (Figure 3a). Likewise, in A549 cell fractionations, endogenous PON3 associated with nuclear, mitochondrial and ER containing fractions, but was absent in supernatants containing soluble proteins (Figure 3b). Mitochondrial localization of PON3 was confirmed by isolation of mitochondria from livers of $\mathrm{PON}^{+1+}$ and $\mathrm{PON}^{-1-}$ mice (Figure $3 \mathrm{c}$ ). This preparation showed negligible crosscontamination of the ER-marker calnexin, or nuclearmarker histone $\mathrm{H} 1$. To determine the submitochondrial localization of PON3, we prepared inner and outer mitochondrial membrane preparations from the livers of these mice. Subsequent western blot analyses revealed that PON3 is predominantly found in the mitochondrial membrane (Figure 3c, middle). Correct separation of mitochondrial membrane was validated with markers for outer or inner mitochondrial membrane (VDAC and COX IV, respectively). As a negative control, PON3 was not detectable in mitochondria isolated from $\mathrm{PON}^{-1-}$ mice (Figure $3 \mathrm{c}$ ).

PON3 impairs mitochondrial oxidative stress. We next investigated if PON3 altered mitochondrial superoxide release. Naive or PON3 overexpressing HEK cells (or PON2 overexpressing cells for comparison) were labeled with mitochondria-targeted dihydroethidium Mito-HE, which specifically reports mitochondrial $\mathrm{O}_{2}^{-}$. Cells were treated with complex III-inhibitor antimycin A, causing a release of $\mathrm{O}_{2}^{-}$to both sides of inner mitochondrial membranes or with complex l-inhibitor rotenone, causing $\mathrm{O}_{2}^{-}$release only to the matrix side. The subsequent FACS analysis 

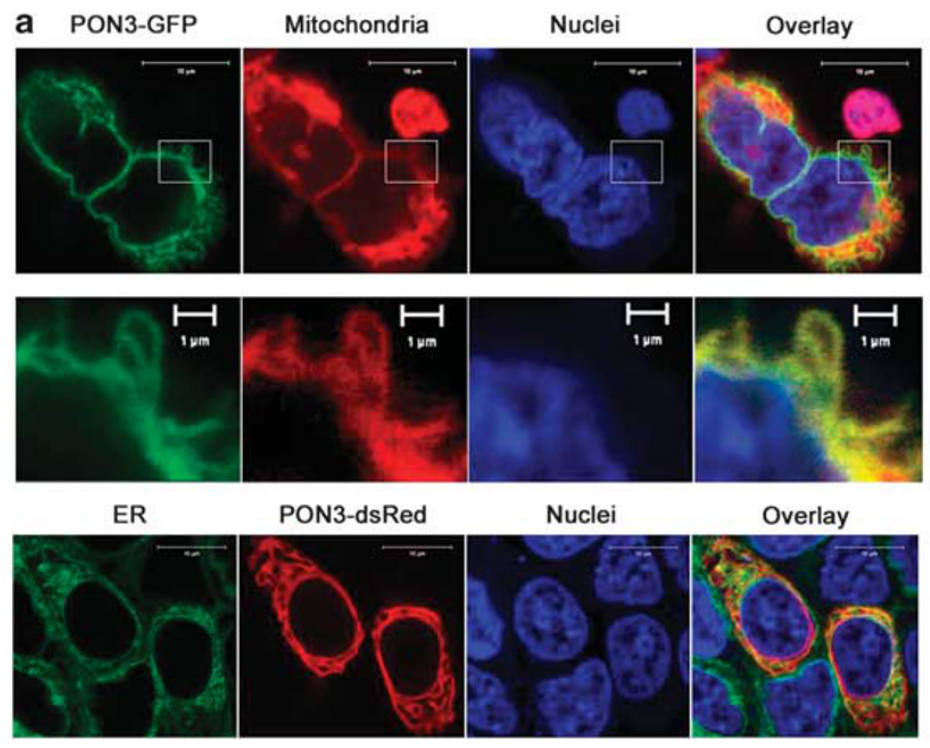

PON3-dsRed

Nuclei

Overlay
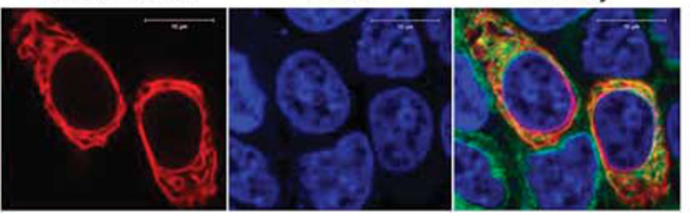

b

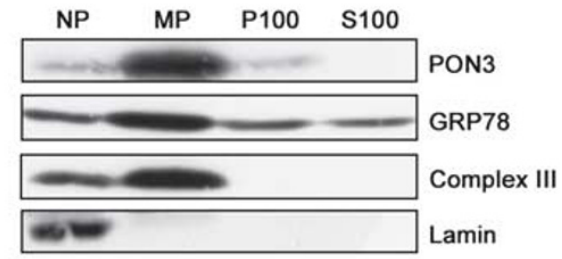

C
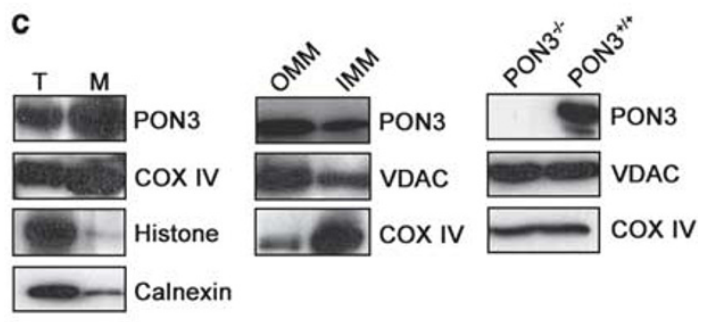

Figure 3 PON3 localizes to the endoplasmic reticulum and mitochondrial membranes. (a) (Upper panel) Live HEK293 cells overexpressing PON3-GFP were stained with reduced MitoTracker Orange (pseudocolored in red); a partial magnification of the indicated area is depicted in the middle panel. (Lower panel) Live HEK293 cells overexpressing PON3-dsRed were stained with ER tracker green dye. Nuclei were stained with Draq5 (pseudocolored in blue). Cells were analyzed by confocal microscopy. Scale bars $=10 \mu \mathrm{m}$ or $1 \mu \mathrm{m}$ (upper/lower and middle panels, respectively). (b) A549 cells were fractionated by differential centrifugation. Protein (50 $\mu \mathrm{g}$ of each fraction) was subjected to western blotting using anti-PON3, anti-GRP78, anti-Complex III and anti-Lamin antibodies. A representative blot out of 2 is shown. NP, nuclear pellet; MP, mitochondrial pellet; S100, $100000 \times g$ supernatant; P100, $100000 \times g$ pellet. (c) Total ('T') and mitochondrial ('M') protein extracts (50 $\mu \mathrm{g})$ isolated from C57BL/6J mouse livers were subjected to SDS-PAGE (left panel). Western blot analyses were performed using anti-PON3, anti-histone and anti-calnexin antibodies. Histone and calnexin served as markers for nuclei and ER, respectively. (Middle panel) Submitochondrial particles were isolated from C57BL/6J mouse livers, and protein (50 $\mu \mathrm{g})$ from outer and inner membrane preparations was subjected to SDS-PAGE. In the shown western blot analyses, VDAC and COX IV are markers for the outer and inner mitochondrial membranes (OMM; IMM), respectively. (Right panel) Mitochondrial membranes isolated from PON $3^{+1+}$ and PON3 ${ }^{-1-}$ mice were subjected to western blot analysis using antibodies against PON3, VDAC and COX IV

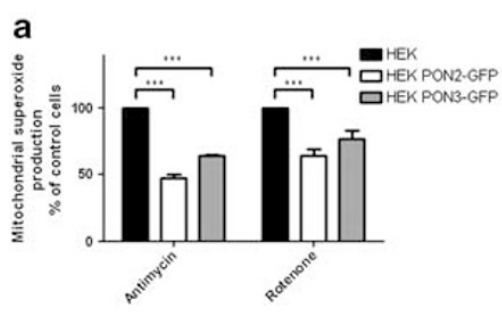

b
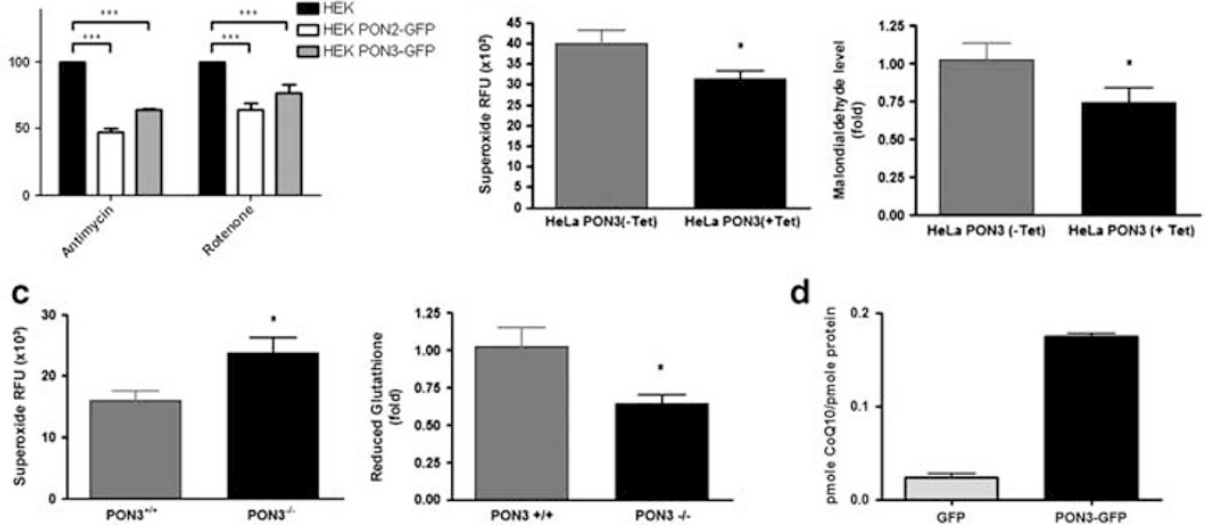

d

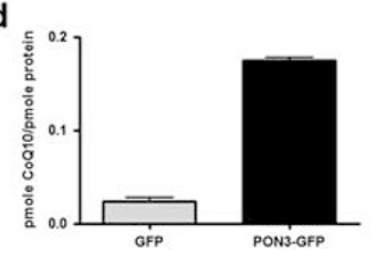

Figure 4 PON3 diminishes mitochondrial superoxide formation and binds CoQ10. (a) Naive, PON2-GFP or PON3-GFP overexpressing HEK293 cells were loaded with Mito-HE $(2 \mu \mathrm{M})$, treated with solvent, antimycin A $(15 \mu \mathrm{M})$ or rotenone $(20 \mu \mathrm{M})$ for $2 \mathrm{~h}$ and analyzed by fluorescence-activated cell sorting (ex/em $405 / 580 \mathrm{~nm})$. (b) HeLa cells stably transfected with a doxycycline-inducible PON3 expression vector (HeLa-PON3), which were either untreated (-Tet) or treated ( + Tet) for $48 \mathrm{~h} \mathrm{with} 2 \mu \mathrm{g} / \mathrm{ml}$ doxycycline, were treated with myxothiazol. Mitochondria were isolated and superoxide was quantified and expressed as relative florescent unit (RFU) (left panel); alternatively, malondialdehyde (right panel) was determined. PON3 overexpression was monitored by western blotting (Supplementary Figure S1). (c) Mitochondria were isolated from $\mathrm{PON}^{+l+}$ or PON3 ${ }^{-l-}$ mice and treated with antimycin at $10 \mu \mathrm{M}$ (left panel). Mitochondrial superoxide levels were quantified after 5 min of treatment and values were represented as RFU; reduced glutathione levels were quantified after 15 min of treatment (right panel). (d) GFP or PON3-GFP was immunoprecipitated from overexpressing HEK293 cells (see Supplementary Figure S2a and b for western blots). Lipids were extracted and co-purifying CoQ10 was quantified using LC/MS/MS. Symbols represent mean \pm S.E.M. $n=3-5 ;{ }^{*} P<0.05 ;{ }^{* \star *} P<0.001$

demonstrated that PON3 (like PON2) significantly diminished mitochondrial $\mathrm{O}_{2}^{-}$production (Figure $4 \mathrm{a}$ ). In a similar approach, the same result was obtained in HeLa cells with tetracycline-inducible overexpression of human PON3
(Supplementary Figure S1) treated with myxothiazol, another complex III-inhibitor (Figure 4b, left). PON3 also decreased malondialdehyde (MDA) levels, a known marker of oxidative stress (Figure 4b, right). 
As PON3 is present in the mitochondrial membrane, we hypothesized that the absence of PON3 might influence mitochondrial oxidative stress in $\mathrm{PON}^{-/-}$mice. We therefore assessed mitochondrial superoxide and glutathione levels in these animals. After brief antimycin A treatment, superoxide levels were increased in mitochondria isolated from livers of $\mathrm{PON}^{-1-}$ mice compared with their controls (Figure 4c, left). Likewise, glutathione levels were significantly decreased (by 35\%) in mitochondria from $\mathrm{PON3}^{-1-}$ mice (Figure $4 \mathrm{c}$, right).

Taken together, PON3 locates to the mitochondrial membrane and prevents $\mathrm{O}_{2}^{-}$formation at both sides of the membrane. As a common denominator for localization and function, this implies PON3 protects against $\mathrm{O}_{2}^{-}$formation by acting on or modulating coenzyme Q10 (CoQ10). In support, LC/MS/MS analysis revealed that CoQ10 co-purified with PON3 immunoprecipitated from HEK293 cells, approximately with $0.175 \mathrm{pmol}$ CoQ10 per pmol PON3 present in the protein preparation (Figure 4d; Supplementary Figure S2a and b). Further, surface plasmon resonance (SPR) analyses using human recombinant PON3 ( $\mathrm{PPON} 3$ derived from insect cells) revealed direct binding of CoQ10 to rPON3 with a $K_{\mathrm{D}}$ of $2.9 \times 10^{-7} \mathrm{M}$ in the presence of $1 \mathrm{mM} \mathrm{CaCl}_{2}$, whereas no binding was observed in the absence of calcium (Supplementary Figure S2c). The affinity of CoQ10 towards PON3GFP derived from HEK cells was found to have a $K_{D}$ of $3 \times 10^{-9} \mathrm{M}$ (data not shown).

PON3 overexpression results in an escape from intrinsic cell death. Next, we addressed the molecular anti-apoptotic function of PON3. Upon induction of the intrinsic apoptotic pathway, mitochondria generate excess superoxide causing peroxidation of a mitochondria-specific lipid, cardiolipin. This disrupts the interaction of cardiolipin with cytochrome $c$, generating a soluble pool of the latter. Together with OMM permeabilization by Bax, this provokes loss of membrane potential and cytochrome $c$ release, together representing a major pro-apoptotic stimulus. Here, we tested if PON3 affected these initial mitochondrial apoptotic steps by treating cells with a potent stimulator of intrinsic apoptosis, PKC inhibitor staurosporine (STS). Importantly, PON3 overexpression rendered cells more resistant to STS cyto-toxicity, as evidenced by diminished cytochrome $c$ release and cardiolipin peroxidation as well as sustained mitochondrial membrane potential and network, that is, morphologic appearance (Figures 5a-d, respectively).

To demonstrate that enhanced PON3 expression indeed results in lowered cell death, the latter was assessed in response to STS or myxothiazol. STS caused significant apoptosis in naive or GFP overexpressing cells. In contrast, overexpression of PON3 (much like PON2) markedly reduced cell death as measured by flow cytometry (annexin-V/7-AAD) of EA.hy 926 cells or intracellular ATP levels in HEK cells (Figures $6 \mathrm{a}$ and $\mathrm{b}$, respectively). Similar results were observed in HeLa cells. Here, tetracycline-induced overexpression of PON3 resulted in preserved ATP levels and significantly decreased TUNEL-positive apoptotic cells after myxothiazol treatment (Figure 6c). Similarly, constitutive overexpression of PON3 lowered actinomycin D
(ActD)-triggered apoptosis (see below) and protected HeLa cells against loss of mitochondrial membrane potential and subsequent apoptosis in response to $\mathrm{H}_{2} \mathrm{O}_{2}$ treatment (Supplementary Figure S3). The latter is in line with PON3 interacting with CoQ10 to preserve integrity of the respiratory electron transport chain (ETC) and mitochondrial function.

The ER stress pathway unfolded protein response (UPR) modulates cell survival highly relevant to cancer and inflammatory processes. Considering localization, anti-apoptotic and anti-inflammatory function of PON3 (see above and Schweikert et al. ${ }^{19}$ ), we assessed if PON3 affected expression of CHOP, a protein centrally involved in life/death decisions of ER stressed cells. ${ }^{20}$ EA.hy 926 cells were treated with tunicamycin and assessed for CHOP mRNA induction. While tunicamycin prominently induced $\mathrm{CHOP}$ in naive cells, this was significantly prevented by overexpression of PON3 (or PON2; Figure 7a). Preceding CHOP induction and serving as underlying mechanism, we demonstrate that PON3 diminished the tunicamycin-induced phosphorylation of JNK (Figure 7b), a kinase whose activation is known to modulate ER stress-triggered CHOP expression. This effect of PON3 on JNK appears to be UPR-specific, since PON3 did not affect JNK (de)-phosphorylation in response to PKC inhibitor STS or PKC activator phorbol myristate acetate (Supplementary Figure S4). Interestingly, this also demonstrates that the protection afforded by PON3 against STS (above) is not mediated via JNK, but by direct mitochondrial effects. In concordance with the effect of PON3 on JNK/CHOP, and CHOP's role in cell death, PON3 also abrogated tunicamycininduced cell death, that is, caspase-3 activation (Figure 7c). Of note, this effect was observed with tunicamycin concentrations even $>10$-fold higher than those needed to induce disruption of mitochondrial membrane potential, ROS, calcium oscillations, GRP78 induction, XBP1 splicing and death of endothelial cells. ${ }^{21}$

We recently showed that PON2 is incapable of attenuating extrinsic apoptosis. ${ }^{15}$ Likewise, PON3 seems ineffective against ligand-stimulated caspase- $3 / 7$ activation in response to TNF- $\alpha$ (in co-treatment with ActD), despite considerable protection against ActD alone, or STS (Figure 7d). Thus, PON3 is unable to alter ligand-mediated cell death in type-I cells (EA.hy 926), where receptor binding sufficiently induces death without mitochondrial involvement. Also, in type-II HeLa cells, PON3 was not able to lower cell death in response to TNF- $\alpha$ (co-treatment with ActD) or TRAIL (Supplementary Figure S5; Figure 7e). This again argues for mitochondrial functions of PON3, which is also confirmed by the result that PON3 protected against the classical DNA damaging agent cisplatin (Figure 7f), known to involve mitochondrial feedback loops.

While PON3 upregulation confers apoptotic-escape, we tested if PON3 deficiency leads to enhanced susceptibility to chemotherapeutics, or if it caused spontaneous cell death. To this end, we knocked down PON3 in A549 or HepG2 cells and analyzed cell death 3 days later by FACS (Figures $8 a$ and b). Despite a sufficient knockdown (Figure 8c), PON3 deficiency neither caused a significant spontaneous apoptosis in either cell line, nor did it enhance susceptibility to STS treatment. In a similar fashion, this was confirmed by measurement of intracellular ATP levels (Figure 8d). 
a
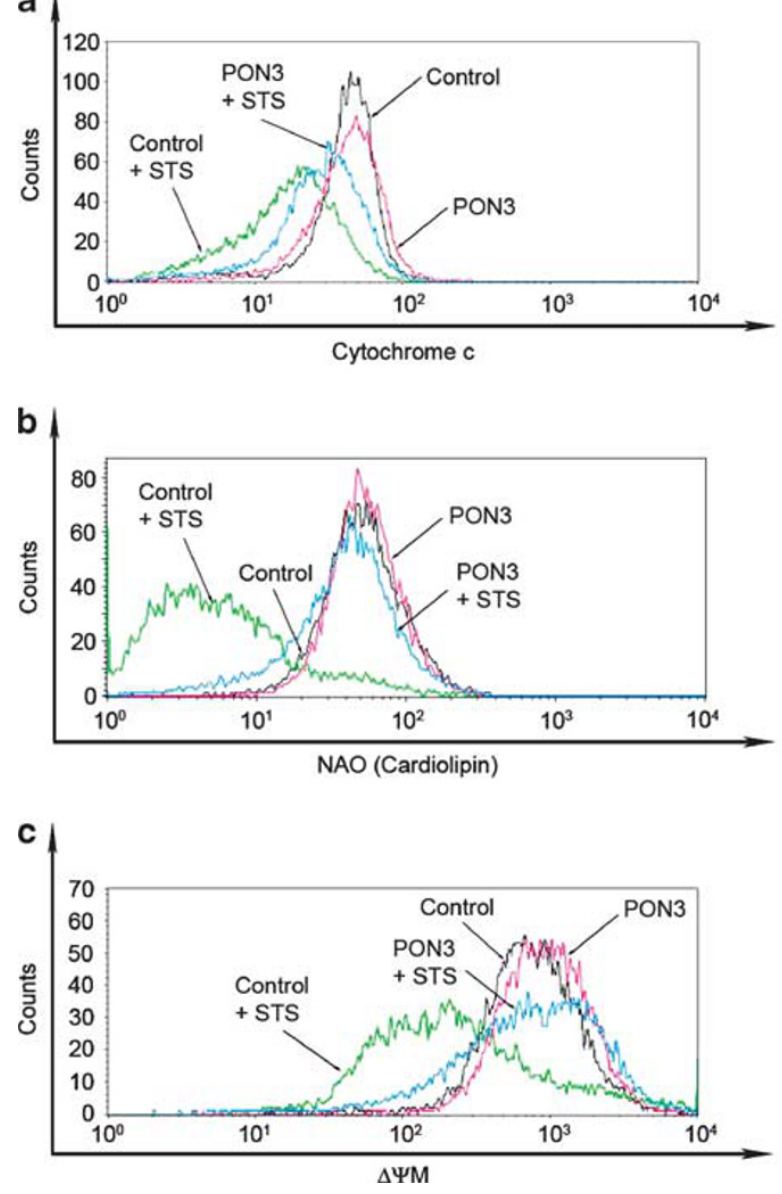

d
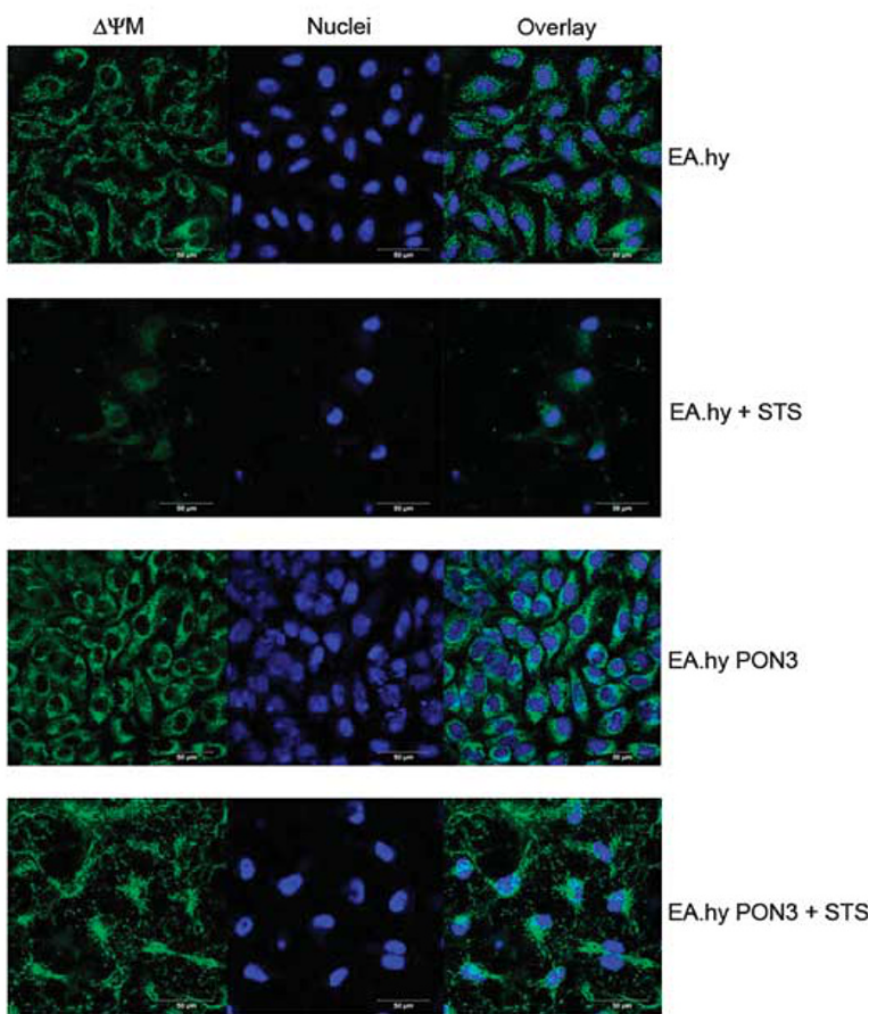

Figure 5 PON3 overexpression reduces cytochrome $c$ release, cardiolipin peroxidation and loss in mitochondrial integrity. (a-c) Naive or PON3-dsRed overexpressing endothelial EA.hy 926 cells were stimulated with staurosporine (STS; $1 \mu \mathrm{M}$ for a and b, $0.3 \mu \mathrm{M}$ for $c$ ) for $16 \mathrm{~h}$. Cells were FACS analyzed for cytochrome $c$ release after immunostaining (a), for cardiolipin peroxidation after NAO staining (b), or for mitochondrial membrane potential $(\triangle \Psi M)$ after DIOC 6 staining $(\mathbf{c})$. A left shift of the peak indicates enhanced cytochrome $c$ release (a), cardiolipin peroxidation (b), or a loss in mitochondrial membrane potential $(\Delta \Psi M$; $\mathbf{c})$ found in naive (green versus black) but not PON3 overexpressing cells (blue versus red). (d) The same cells were stimulated with STS $(0.3 \mu \mathrm{M})$ for $24 \mathrm{~h}$ and stained for mitochondrial membrane potential (DIOC 6 ; green) or nuclei (Draq5; blue), followed by confocal imaging. Note that naive cells showed both reduced fluorescence intensity and mitochondrial network integrity, which was largely sustained by PON3 overexpression. Scale bars $=50 \mu \mathrm{m}$

\section{Discussion}

This study provides evidence, for the first time, that human PON3 is markedly overexpressed in a variety of human neoplasias and that enhanced PON3 expression confers apoptotic resistance to tumor cells. Previous studies characterized the enzymatic activity of PON3 and demonstrated its role in protection against obesity and atherosclerosis. Apparently, its effect was due to mitigation of cellular lipid peroxide content and inhibition of cell-mediated LDL oxidation. ${ }^{7,22}$ Most likely, this was as consequence of its antioxidative function, which may require unknown cofactors as human PON3 did not protect LDL against copper-induced oxidation in vitro. ${ }^{5}$ Remarkably, it now appears that the same activity defines an anti-apoptotic and unanticipated oncogenic role in human cancers. Our data show that PON3 directly acts at mitochondria and associates with mitochondrial membranes. Presently, it is unknown how PON3 enters these membranes. Various software tools give only moderate probability of mitochondrial localization for PON2 and PON3 proteins.
Also, (cleavable) targeting sequences were not identified by some programs, whereas Mitoprot II software tool (http://ihg.gsf. de/ihg/mitoprot.html) predicted the existence of a mitochondrial targeting sequence for PON2; however, the same software tool did not identify targeting sequences for either PON3 or cytochrome c (a well-known mitochondrial protein). In addition, a putative interaction with membrane receptors has not been studied to our knowledge. Nonetheless, according to analyses of PON3 primary sequence and correlation with the structure of PON1, the $\mathrm{N}$-terminus most likely serves a membraneattaching region and may harbor enough positively charged residues and amphiphilicity required for mitochondrial import. Despite this unsolved issue, the present functional data demonstrate that PON3 abrogates superoxide formation at both sides of the inner mitochondrial membrane. Given the interaction with CoQ10, this occurs presumably by sequestering unstable ubisemiquinone produced by the ETC. This may reprogram energy metabolism, but in any case attenuates $\mathrm{O}_{2}^{-}$-triggered cardiolipin peroxidation, which subsequently controls mitochondrial cytochrome $c$ release-a master-regulator of cell 
a
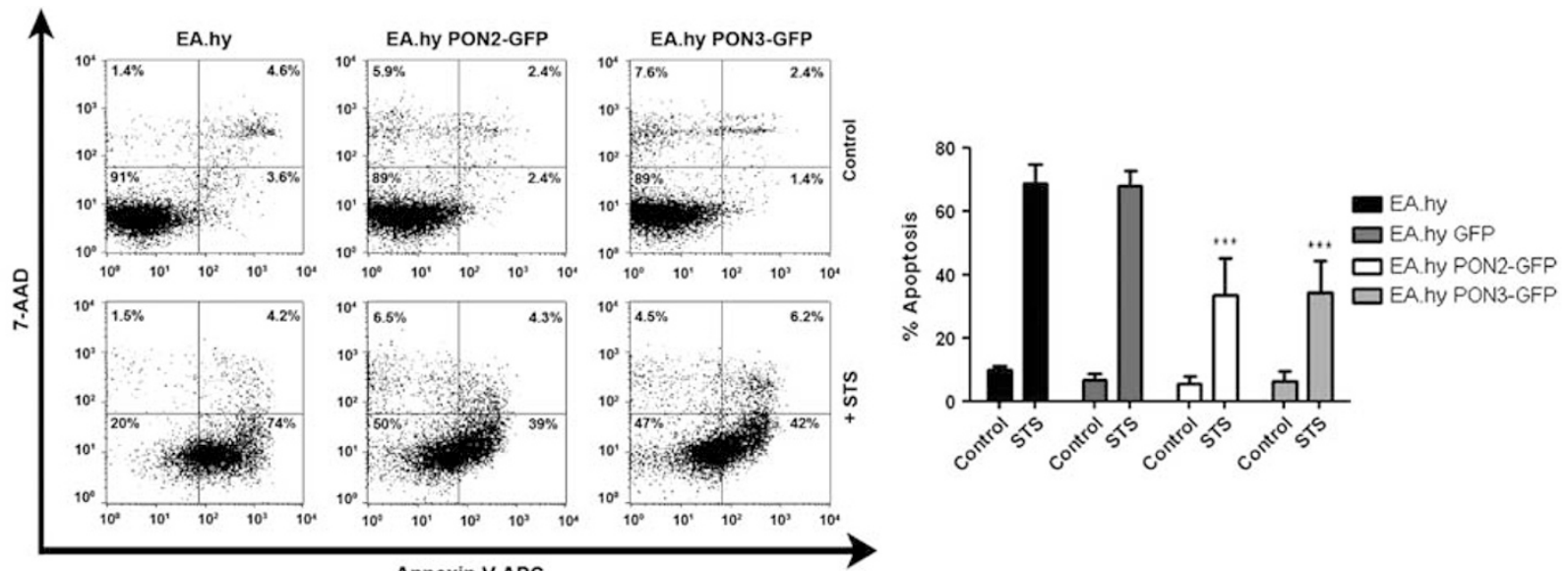

Annexin V APC
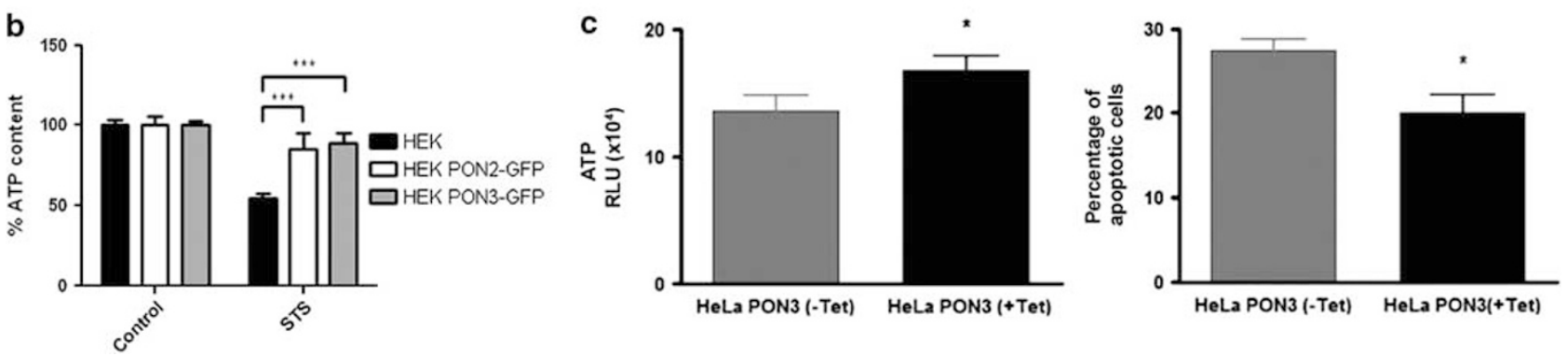

Figure 6 PON3 overexpression reduces intrinsic apoptosis. (a) Naive, PON2-GFP or PON3-GFP overexpressing EA.hy 926 cells were treated with STS (16 h; $1 \mu \mathrm{M}$ ) and analyzed for annexin-V/7-AAD by FACS. One representative experiment is shown (left); three independent experiments were summarized (right). (b) Indicated HEK cells were treated with STS $(48 \mathrm{~h} ; 5 \mu \mathrm{M})$ and assessed for intracellular ATP levels. (c) HeLa cells stably transfected with doxycycline-inducible PON3 expression (HeLa-PON3) or empty vector (HeLa-EV) were treated with myxothiazol. ATP (left panel) and apoptosis (right panel) were quantified as described in Materials and Methods. PON3 overexpression was monitored by western blotting (Supplementary Figure S1). Symbols represent mean \pm S.E.M. $n=3-5 ;{ }^{\star} P<0.05 ;{ }^{* \star \star} P<0.001$

death. ${ }^{23}$ From such perspective, upregulation of PON3 in cells destined for apoptotic evasion appears consequential.

We show that PON3 is markedly upregulated in a variety of different human tumors, characterize its expression in several cancer cell lines and document its localization to ER and predominantly mitochondrial membranes. By employing several technical approaches in different human cell culture systems together with $\mathrm{PON}^{-1-}$ mice, we reveal that PON3, by binding to CoQ10 reduces mitochondrial $\mathrm{O}_{2}^{-}$production. This is evidenced by direct measurement as well as attenuation of oxidative stress markers and signaling steps subsequent to ROS formation. Importantly, this function of PON3 cumulates in mitigation of ROS-triggered cell death specific for ER stress-/DNA damage-induced and intrinsic (but not extrinsic) apoptosis. PON3's hydrolytic function and physiological substrates remain elusive. However, our findings imply that diminished mitochondrial $\mathrm{O}_{2}^{-}$is a key process in PON3's action and reveal its natural role as crucial mediator of cellular resistance to physiologic oxidative stress. In addition, PON3 also protects against UPR-mediated $\mathrm{CHOP}$ expression, a pathway critically implemented, for example, in atherosclerosis, inflammation and cancer. The ER stress pathway is regarded as a target of emerging therapeutic approaches with CHOP playing a fundamental role in life/ death decisions of stressed cells. ${ }^{3,24}$
At first glance, the functions and effects of PON2 and PON3 relative to their putative role in cancer cells appears similar: both are overexpressed in cancer tissues, locate to mitochondria, abrogate superoxide production and help tumor cells to resist chemotherapeutics and cell death (this study and $\left.{ }^{12,13,15}\right)$. However, one obvious difference is the level to which the two PONs are overexpressed in cancer tissues, as this was usually much higher for PON3. Little is known about regulatory pathways controlling PON2 and especially PON3 expression, with $\mathrm{PON} 2$ responding to $\mathrm{AP}-1 / \mathrm{JNK}$ signaling, ${ }^{25}$ PI3K/PDGFR- $\beta^{26}$ and ER stress, ${ }^{14}$ while differences exist in their response, for example, to oxidative stress ${ }^{27}$ or high-fat, high cholesterol diet. ${ }^{7}$ Expression of PON2 and PON3 in response to inflammatory mediators such as LPS, TNF- $\alpha$, IFN- $\gamma$ or IL- $1 \beta$ remains somewhat controversial; ${ }^{28,29}$ however, the expression did not appear to have a major impact on the systems tested. Conversely, other findings suggest modulation of local inflammatory responses by PONs presumably due to reduction of ROS and/or metabolism of lipid mediators. ${ }^{5}$ Another major difference is spontaneous induction of apoptosis in some tumor cell lines in response to PON2 knockdown, ${ }^{15}$ which appeared absent for PON3. One explanation may be that we did not find tumor cells utterly susceptible to PON3 knockdown (likewise, half of the tested cancer cells did not respond to PON2 knockdown ${ }^{15}$ ); another 
a

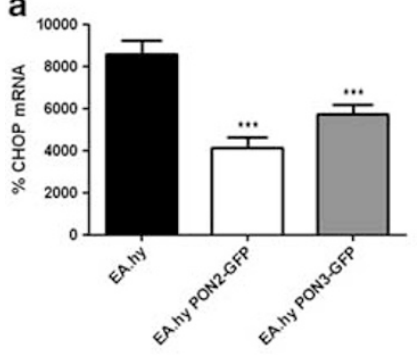

d

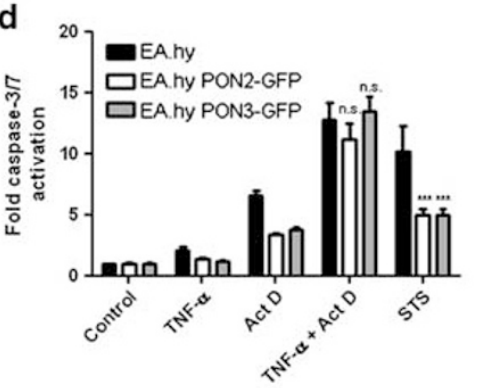

b

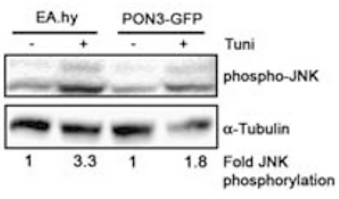

C

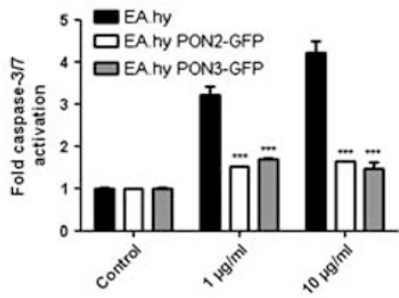

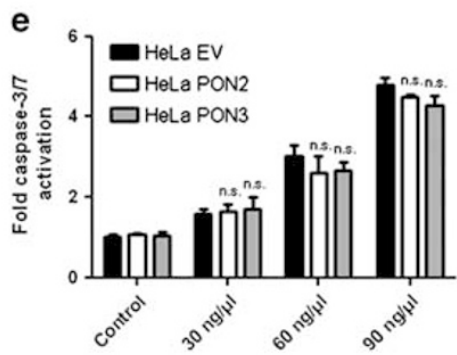

f
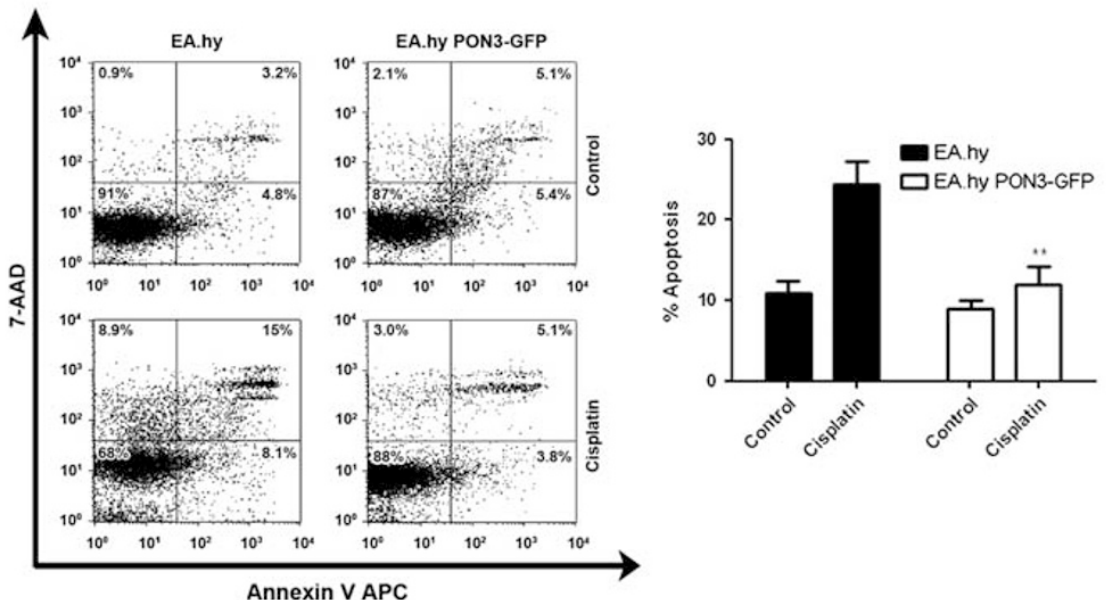

Annexin V APC

Figure 7 PON3 overexpression reduces ER stress- or DNA damage-, but not ligand-induced apoptosis. (a) Naive, PON2-GFP or PON3-GFP overexpressing EA.hy 926 cells were treated with tunicamycin $(16 \mathrm{~h} ; 1 \mu \mathrm{g} / \mathrm{ml})$ and analyzed for CHOP mRNA expression by qRT-PCR. (b) Indicated cells were treated with tunicamycin (30 min; $1 \mu \mathrm{g} / \mathrm{ml})$ and analyzed for phospho-JNK levels by western blot. (c) The same cells were treated with tunicamycin $(24 \mathrm{~h} ; 1 \mathrm{or} 10 \mu \mathrm{g} / \mathrm{ml})$ followed by assessment of caspase-3/7 activation. (d) Indicated cells were treated $(16 \mathrm{~h})$ with TNF- $\alpha(200 \mathrm{U})$ or ActD $(1 \mu \mathrm{g} / \mathrm{ml})$ or both, or staurosporine $(1 \mu \mathrm{M})$ and assayed for caspase-3/7 activation. (e) HeLa cells stably transfected with PON2, PON3 or empty vector (EV) were treated for $8 \mathrm{~h}$ with TRAIL at the indicated concentrations and analyzed as before. (f) Naive or PON3-GFP overexpressing EA.hy 926 cells were treated with cisplatin $(72 \mathrm{~h} ; 4 \mu \mathrm{g} / \mathrm{ml})$ and analyzed for annexin-V/7-AAD by FACS. One representative experiment is shown (left); three independent experiments were summarized (right). Symbols represent mean \pm S.E.M. $n=3-9$; n.s., not significant; ${ }^{\star} P<0.05 ;{ }^{* \star} P<0.01 ;{ }^{* \star *} P<0.001$

argument may be the overall low expression level of PON3 (compared with PON2). Nevertheless, its overexpression grants robust anti-oxidative and anti-apoptotic benefit to tumor cells, thus overexpressed PON3 might constitute an attractive anti-cancer target.

The PON family consists of three enzymes and we now showed that two of them (PON2 and PON3) are overexpressed in cancers and abrogate cell death (this study and $^{15}$ ). Given the high similarity of the three PONs, one may consider a similar role for PON1. While human PON2 and PON3 locate to the center of cell death regulation, that is, mitochondria and the ER, PON1 is almost exclusively found on circulating $\mathrm{HDL}$ particles and thus appears unlikely to modulate intracellular redox-triggered death pathways.
However, an intriguing observation reported that PON1 can redistribute from lipoprotein particles back to cell membranes while retaining its enzymatic and anti-oxidative function. ${ }^{30}$ From such perspective, it appears worth investigating if cancer cells scavenge PON1 from the circulation to exploit its anti-oxidative effect for cell death escape. Generally, such a hypothesis might be supported by studies linking PON1 genotypes, for example, to renal carcinomas, breast, ovarian and prostate cancer (as reviewed elsewhere ${ }^{31}$ ). However, it yet remained uncertain which function of PON1 was of major importance, its hydrolytic activity or anti-oxidative effect. Reduced serum PON1 activity was also found in several malignancies, although this does not provide any clues about protein levels within specific cancer cells. Together, 
a
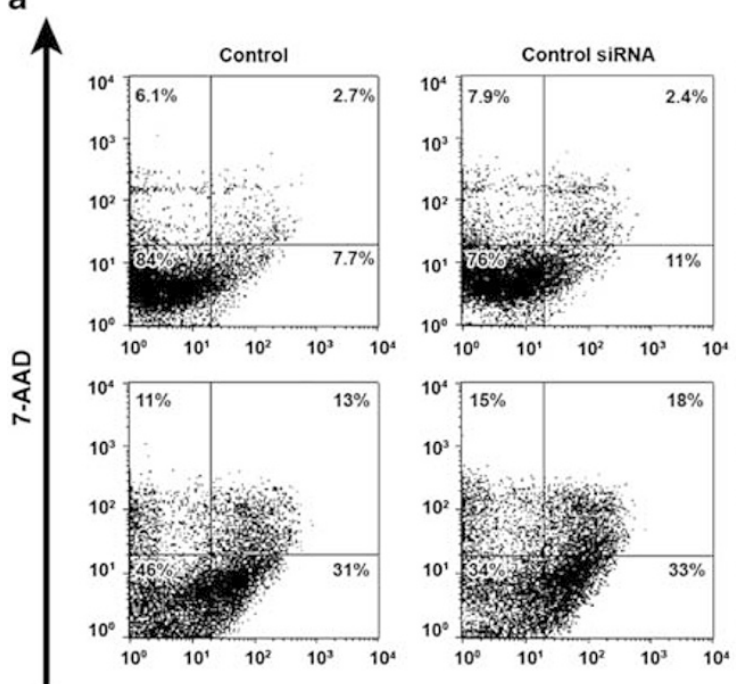

Annexin V APC

\section{b}
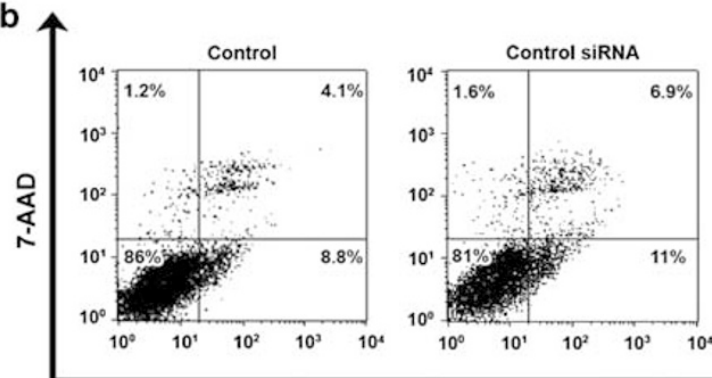

Annexin V PE

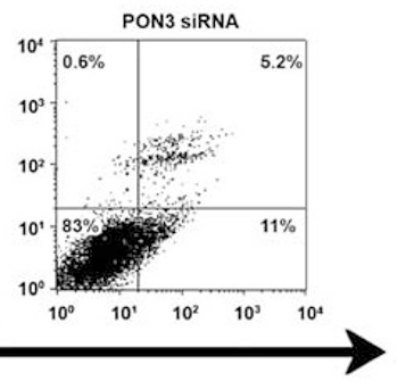

C

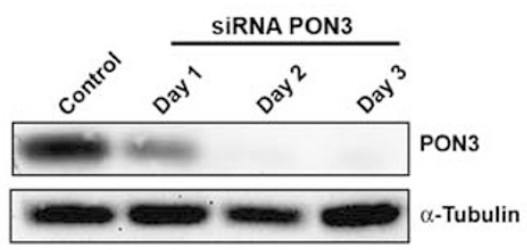

d

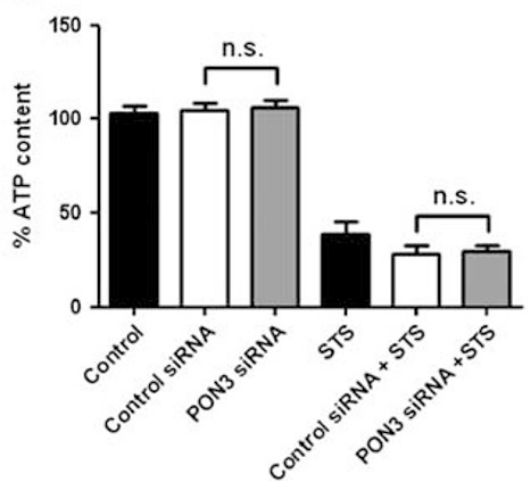

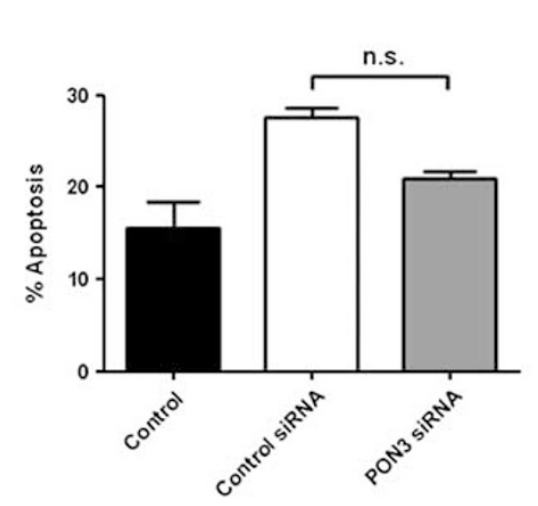

A549
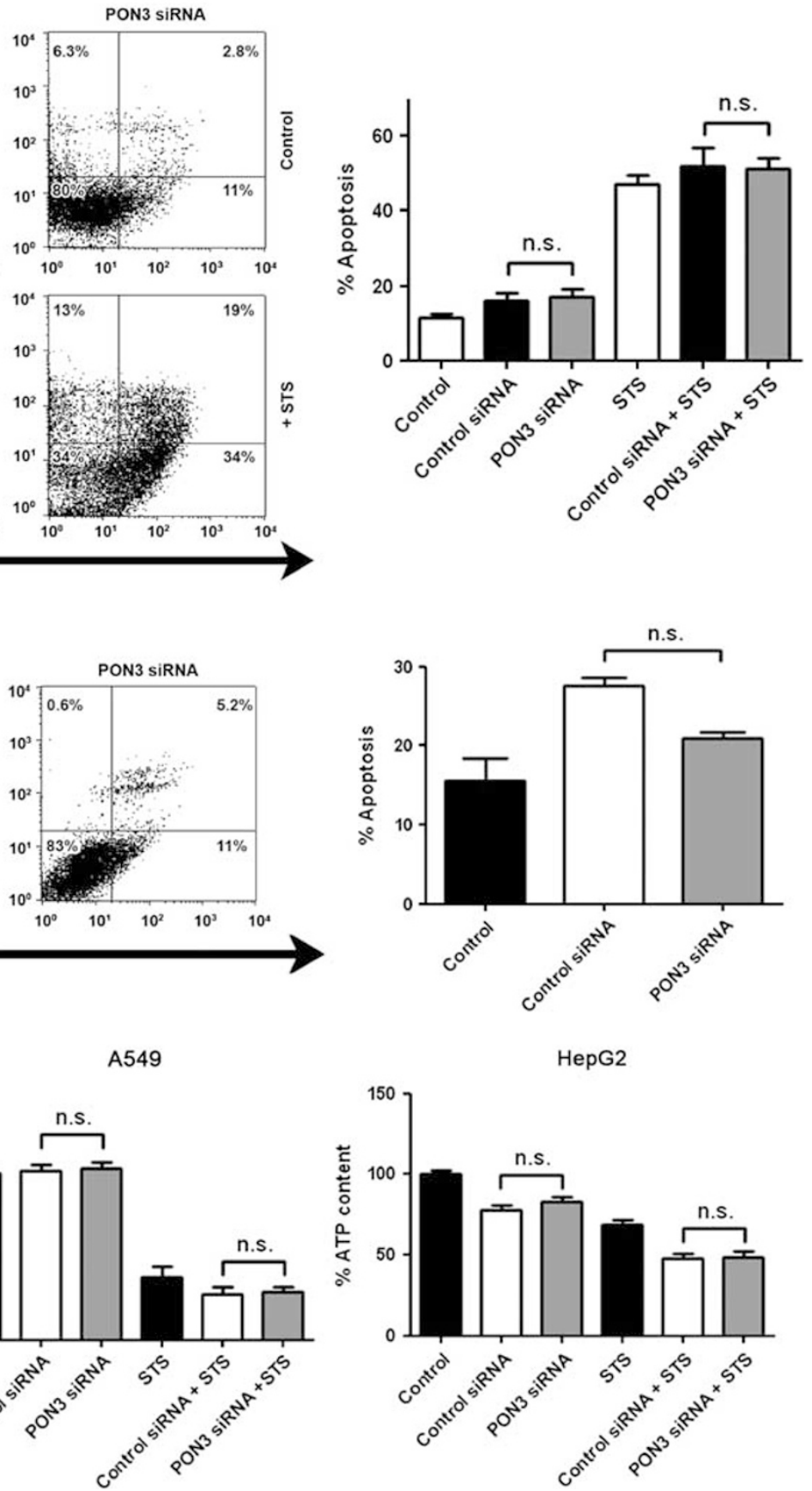

Figure 8 PON3 deficiency does not cause spontaneous cell death of A549 or HepG2 cells. (a) A549 cells were left untreated or were treated with control or PON3-specific siRNAs for 3 days. Alternatively, cells were siRNA treated for 2 days, followed by another $24 \mathrm{~h}$ stimulation with staurosporine $(1 \mu \mathrm{M})$. Subsequently, cell death was assessed by FACS (annexin-V/7-AAD). One representative experiment is shown (left); three independent experiments were summarized (right). (b) HepG2 cells were left untreated or were treated with control or PON3-specific siRNAs for 3 days. Cell death was assessed as in (a). (c) A549 cells were left untreated or were treated with PON3-specific siRNAs for 1-3 days. Protein (30 $\mu \mathrm{g}$ of each fraction) was subjected to western blotting using anti-PON3 and anti- $\alpha$-tubulin. (d) A549 or HepG2 cells treated as in (a) and analyzed for intracellular ATP content after 3 days. Symbols represent mean \pm S.E.M. $n=3-9 ;$ n.S., not significant

addressing PON1 could complete a new role for PONs in cell death regulation, with $\mathrm{PON} 2$ and PON3 acting from intracellular compartments, whereas PON1 may be supplied from the circulation.
A future direction addressing PON3 in cancer may employ murine models with either (conditional) overexpression of transgenic human PON3 or PON3 knockout animals. Shih and co-workers have recently established a transgenic model 
for PON3, and confirmed previous findings that human and mouse PON3 differ in their tissue expression pattern. ${ }^{27,32}$ Thus, studies employing murine PON3 may suffer from certain limitations or demand careful verification of localization and function. Moreover, the physiologic role of its hydrolytic activity is unclear and due to yet unresolved mechanisms, gender-specific effects have been observed for PON3 relative to atherosclerosis and adiposity. ${ }^{32}$ Therefore, to address PON3 in human cancers one may utilize primary tumor material and analyze its usefulness in new appropriate in vivo models. If successful, such studies could reveal its clinical relevance and initiate new therapeutic strategies targeting PON3. Beyond this specific enzyme family, our findings demonstrate the importance of particular redox regulatory system for oncogenic transformation and outline their usefulness as target structures in therapeutic cancer management.

\section{Materials and Methods \\ Cell culture, mice and material. Human endothelial EA.hy 926 cells were cultured in Dulbecco's modified Eagle's medium without Phenol Red (Sigma, St. Louis, MO, USA) containing sodium pyruvate (PAA Laboratories, Pasching, Austria), antibiotics penicillin/streptomycin, hypoxanthine/aminopterin/thymidine supplement, GlutaMAX (Gibco/Invitrogen, Carlsbad, CA, USA) and 10\% (v/v) PAA gold serum (PAA Laboratories). Human PON3 CDNA was subcloned into pDsRed-Express-N1 or pEGFP-N1 plasmids (Clontech, Mountain View, CA, USA). Stable cell lines, plasmids and transfection procedures were described before. ${ }^{14,33}$ HEK293 and A549 cells were from the German Collection of Microorganisms and Cell Cultures. HEK293 received the same medium as EA.hy 926, but without hypoxanthine/aminopterin/thymidine supplement. A549 and HepG2 (a kind gift from $T$ Heise; University Medical Center South Carolina, USA) received the same medium as HEK293, but $5 \%$ serum. Cells were cultured at $37^{\circ} \mathrm{C}$ in a humidified atmosphere under $5 \% \mathrm{CO}_{2}(10 \%$ for EA.hy 926). All other cell lines or lysates thereof were kind gifts from B Köberle (833K, SuSa, GCT27, HT1376, RT112, MGHU-1) and C Dietrich (Caco-2), Department of Toxicology, Mainz, H Kleinert (C28I, Jurkat) and E Closs (DLD-1, U373), Department of Pharmacology, Mainz. PON3 ${ }^{-1-}$ mice were described (DM Shih, JM Yu, YR Xia, YS Shi, X Ping; LC Wang, P Zhang, Z Port, MD Champion, DA Ford, K Reue, AJ Lusis. Altered lipid metabolism and increased atherosclerosis in the paraoxonase 3 knockout mice. Arteriosclerosis, Thrombosis and Vascular Biology, Scientific Sessions 2010, P141 page e211). STS, tunicamycin, ActD, percoll, antimycin, myxothiazol, cisplatin and rotenone were purchased from Sigma; Mito-HE was from Molecular Probes; TNF- $\alpha$ was from Miltenyi Biotec (Bergisch Gladbach, Germany).}

Cancer survey panels. PON3 expression levels were determined in cancer versus normal tissues by quantitative real-time PCR using TissueScan Cancer Survey Panel-III $(4 \times 96$-well format) normalized to $\beta$-actin and GAPDH as described before. ${ }^{15}$ In addition, we determined PON3 cDNA levels in 24 samples from patient-matched TissueScan matched Lung Cancer Panel-IV (Origene, Rockville, MD, USA). See supplier's homepage (http://www.origene.com/qPCR/ Tissue-qPCR-Arrays.aspx) for details on the tissues and comprehensive pathology reports.

Expression of PON3 in human ovarian cancer tissue. Tissue samples from patients with ovarian cancer or adjacent normal tissue were obtained through the Gynecological Oncology Group and Cooperative Human Tissue Network. Total tissue protein lysates were analyzed by western blotting for goatanti-PON3 (used at 1:500; R\&D Systems, Minneapolis, MN, USA) and GAPDH antibodies (used at 1:1000, Santa Cruz Biotechnology Inc., Delaware Avenue, CA, USA).

PON3 expression in several (tumor) cell lines. Preparation of total protein lysates, SDS-PAGE and western blotting using a semi-dry transfer system (Bio-Rad, Hercules, CA, USA) was performed as described previously. ${ }^{14,33}$ Rabbitanti-PON3 polyclonal antibody was used at 1:750 (Sigma), rabbit-anti-PON $2^{14}$ was used at 1:2000, mouse-anti-GAPDH was used at 1:5000 (Santa Cruz
Biotechnology); HRP-conjugated secondary antibodies were purchased from Sigma.

Immunocytochemistry. Cells stably expressing PON3-GFP or PON3dsRed were seeded in Lab-Tek chamber slides (Nunc), washed with HBSS, stained with $5 \mu \mathrm{M}$ Draq5 (Cell Signaling Technology, Danvers, MA, USA) and $1 \mu \mathrm{M}$ MitoTracker Orange (Molecular Probes, Invitrogen/Life Technologies, Carlsbad, $\mathrm{CA}, \mathrm{USA}$ ) or $1 \mu \mathrm{M}$ ER tracker red dye (Invitrogen) for $20 \mathrm{~min}$ at $37^{\circ} \mathrm{C}$, washed and suspended in growth medium. Analysis by confocal laser scanning microscopy was performed with a Zeiss LSM-710, equipped with ZEN2008 software (Zeiss, Jena, Germany), using a Plan/Apochromat $\times 63 / 1.4$ oil DIC objective. Appropriate wavelengths were sequentially scanned; absence of cross-emission was verified (data not shown).

Isolation and purity assessment of submitochondrial particles and localization of PON3. A549 cells were fractionated by differential centrifugation as described before ${ }^{12}$ with subsequent preparation of lysates, SDSPAGE and western blotting as reported earlier. ${ }^{14,33}$ Rabbit-anti-PON3 polyclonal antibody was used at 1:750 (Sigma), goat-anti-GRP78 was used at 1:750 (Santa Cruz Biotechnology), mouse-anti-Complex III subunit core 2 was used at 1:1000 (MitoSciences, Eugene, OR, USA) and goat-anti-Lamin C-20 was used at 1:1000 (Santa Cruz Biotechnology); HRP-conjugated secondary antibodies were from Sigma.

Mitochondria and submitochondrial particles were isolated from the livers of $\mathrm{PON}^{+1+}$ or PON3 ${ }^{-1-}$ mice on C57BL/6J background as described previously, ${ }^{34-36}$ and their protein extracts (50 $\mu$ g per sample) were resolved by $4-15 \%$ SDS-PAGE, transferred onto nitrocellulose membranes and blocked in TBS containing $3 \%$ milk protein for $1 \mathrm{~h}$. Mouse or human PON3 antibody were used at 1:500 (R\&D Systems), Histone 1 antibody was used at 1:250 (Santa Cruz Biotechnology), Calnexin antibody was used at 1:1000 (Assay Designs, Ann Arbor, MI, USA), antivoltage-dependent anion channel 1 was used at 1:500 (Cell Signaling Technology), human cytochrome oxidase antibody was used at 1:500 and mouse cytochrome oxidase antibody was used at 1:250 dilution (Cell Signaling Technology). Primary antibodies were diluted in TBS containing $5 \%$ milk protein at $4{ }^{\circ} \mathrm{C}$ overnight. The membranes were probed with their respective secondary antibodies (1:5000) for $1 \mathrm{~h}$ and proteins illuminated using an ECL Plus Western blotting kit (GE Healthcare, Chalfont St. Gilles, UK).

Assessment of mitochondrial oxidative stress. Mitochondrial superoxide detection in HEK293 cells was performed as described by Altenhöfer et al..$^{12}$ (Figure $\left.4 \mathrm{a}\right)$. Mitochondrial enriched fractions (100 $\mu \mathrm{g}$ protein) from livers of $\mathrm{PON}^{+1+}$ or $\mathrm{PON}^{-1-}$ mice were treated with anti-mycin at $10 \mu \mathrm{M}$ for $5 \mathrm{~min}$. Subsequently, mitochondrial superoxide was quantified as described elsewhere ${ }^{37}$ (Figure 4b). After $15 \mathrm{~min}$, mitochondrial glutathione was quantified as described by the manufacturer's protocol (Cayman Chemical Company, Ann Arbor, MI, USA).

PON3 overexpression studies. HeLa cell line stably overexpressing the human PON3 gene under control of a tetracycline-inducible promoter were treated first with $2 \mu \mathrm{g} / \mathrm{ml}$ of doxycycline for $48 \mathrm{~h}$ or left untreated, ${ }^{8}$ followed by $10 \mu \mathrm{M}$ myxothiazol for $6 \mathrm{~h}$ which is known to inhibit ETC and induce superoxide ex vivo. ${ }^{38,39}$ After treatment, mitochondrial superoxide, glutathione (Cayman Chemical Company), MDA (Cayman Chemical Company) and ATP levels were quantified as described. ${ }^{13}$ After $24 \mathrm{~h}$ of treatment, apoptosis was assessed using TUNEL assay (Promega, Madison, WI, USA).

In another set of experiments, after induction with doxycycline, these cells were treated with $300 \mu \mathrm{m}$ hydrogen peroxide for $5 \mathrm{~h}$ and apoptotic nuclei were quantified using TUNEL assay (Promega). After induction with doxycycline, total proteins were extracted and PON3 was detected by western blot.

For overexpression of PON2/PON3, HeLa cells were transfected with PON2 or PON3 cloned into pcDNA 3.1 at Hindlll and Xho1 site. These cells were treated with STS or TNF- $\alpha$, ActD and TRAIL as described in the figure legends (Figure 7e, Supplementary Figure S5). Caspase-3/7 activity was measured according to the manufacturer's protocol (Promega Corporation).

Detection of phospho-JNK. Preparation of lysates, SDS-PAGE and western blotting was performed as reported previously. ${ }^{33}$ Rabbit-anti-phosphoSAPK/JNK (Thr183; Tyr185) (Cell Signaling Technology) was used at 1:1000 and mouse-anti-Tubulin Ab2 (Dianova, Hamburg, Germany) was used at 1:2000; HRP-conjugated secondary antibodies were from Sigma. 
Purification of PON3-GFP and analysis of Coenzyme Q10 content . Mitochondria were isolated from HEK GFP or HEK PON3-GFP cells as described above. Mitochondrial pellet was resuspended to a final protein concentration of $10 \mathrm{mg} / \mathrm{ml}$ in $20 \mathrm{mM}$ Tris- $\mathrm{HCl}, \mathrm{pH} 7.5,0.5 \mathrm{mM}$ EDTA, $1 \%$ dodecyl maltoside and $1 \mathrm{M} \mathrm{NaCl}$, centrifuged at $10000 \times g$ for $10 \mathrm{~min}$, and the resulting supernatants were subjected to GFP purification protocol ( $\mu$ MACS GFP isolation Kit, Antibody Online, Atlanta, GA, USA). GFP and PON3-GFP were detected by western blotting using PON3 antibody (R\&D Systems) and anti-GFP antibody (Biovision, Milpitas, CA, USA). Equal concentrations of isolated proteins were subjected to lipid extraction as described. ${ }^{40}$ The combined organic phase was dried under nitrogen gas and resuspended in $200 \mu \mathrm{l}$ of ethanol, and LC-MS/MS analysis for CoQ10 was performed as described elsewhere ${ }^{40}$ using a 4000 QTRAP linear MS/MS spectrometer from Applied Biosystems (Foster City, CA, USA). All samples were analyzed in multiple reaction monitoring mode (MRM); MRM transitions were as follows: $\mathrm{m} / \mathrm{z} 880.7 / 197.0$ (CoQ10 with ammonium adduct), $m / z$ 882.7/197.0 $\left(\mathrm{Q}^{10 \mathrm{H}_{2}}\right.$ with ammonium adduct), and $m / z$ 908.7/225.1 (Diethoxy-Q10 with ammonium adduct). Diethoxy-Q10 was used as an internal standard. Applied Biosystem software, Analyst version 1.4.2, was used for data acquisition and processing

Coenzyme Q10 (CoQ10) binding studies by SPR. PON3 and CoQ10 binding studies were carried out using SPR on a BIAcore 3000 system. Human recombinant PON3 was expressed and purified as described previously. ${ }^{5}$ Alternatively, PON3 was purified from HEK PON3-GFP overexpressing cells (see above). Briefly, the protein was immobilized on BIAcore CM5 sensor chip activated per the manufacturer's protocol with $N$-hydroxysuccinimide and 1-ethyl-3(3-dimethylaminoisopropyl) carbodiimide. After achieving adequate immobilization, the sensor surface was deactivated with ethanolamine. Analyte solutions were prepared in a standard BIAcore buffer (HBS-N), containing 10 mM HEPES, pH 7.4 and $150 \mathrm{mM} \mathrm{NaCl}$ in the presence or absence of $1 \mathrm{mM} \mathrm{CaCl}_{2}$. Lipid stock solutions (phosphatidyl ethanolamine and CoQ10) were prepared in ethanol, so that analytecontaining, HBS-N binding buffer contained up to $1 \%$ ethanol. Lipid binding was measured by observing the change in the SPR signal as $150 \mu \mathrm{l}$ of lipid (various concentrations) in HBS-N buffer flowing over the chip for $3 \mathrm{~min}$ at $50 \mu \mathrm{l} / \mathrm{min}$. Equilibrium affinity constant $\left(K_{D}\right)$ values were calculated from assays performed with different concentrations that gave binding responses of 30 to $>500$ resonance units. The calculations were done with BIAcore's BIAevaluation software (BIAcore, GE Healthcare), version 4.1, assuming a molar ratio of 1:1 lipid:protein binding. Al experiments were done at the SPR Core at the University of California, Los Angeles.

Assessment of apoptosis by flow cytometry. Cells were stained with annexin-V-phycoerythrin (or annexin-V-APC) and 7-amino-actinomycin (apoptosisdetection-kit-l; BD Biosciences, Franklin Lakes, NJ, USA) as recommend by the manufacturer; 10000 fluorescent events were acquired using a FACS-Calibur equipped with CellQuest Pro software (BD Biosciences).

Assessment of membrane potential by flow cytometry. Cells grown in 24-well dishes were trypsinized, resuspended in growth medium, pelleted $\left(350 \times \mathrm{g}, 4^{\circ} \mathrm{C}, 5 \mathrm{~min}\right), 30 \mathrm{~min}$ stained with $25 \mathrm{nM} \mathrm{DIOC}_{6}$ (Molecular Probes), re-centrifuged and washed in chilled PBS, re-centrifuged and fixed in $2 \%$ paraformaldehyde (in PBS). Fixed cells were analyzed by flow cytometry.

RNA interference. Cells at $60 \%$ confluency were transfected with $25-70 \mathrm{nM}$ PON3-specific smart-pool siRNAs (a mix of four different siRNAs each; Dharmacon) or scrambled siRNA (Invitrogen) using Saint-Red reagent (Synvolux, Groningen, The Netherlands) according to the manufacturer's protocol.

Other methods not listed here such as determination of ATP content, caspase activity, cytochrome $c$ release, cardiolipin peroxidation or membrane potential by confocal microscopy were performed as described before. ${ }^{12,15}$

Software, statistics and image acquisition. GraphPad Prism-5 (La Jolla, CA, USA) was used for calculations, statistical evaluation using one-two-way ANOVA with Bonferroni's multiple comparisons post-test (see figure legends, Figures 2, 4, 6-8, Supplementary Figures S3 and S5). $P<0.05$ was considered significant. Adobe Photoshop software (München, Germany) was used for image acquisition. If necessary, only brightness and/or contrast were changed simultaneously for all areas of any blot.

\section{Conflict of Interest}

The authors declare no conflict of interest.
Acknowledgements. Work in the laboratory of $\mathrm{S}$ Horke has been financially supported by intramural funds of the University Mainz or the University Medical Center of the JGU Mainz and by the German Research Foundation, Deutsche Forschungsgemeinschaft, Project HO-3924/4-1. Work in the laboratory of ST Reddy has been financially supported by the National Heart, Lung and Blood Institute (NHLBI; Grant number 1R01HL71776). We thank Dr. Catherine F Clarke and Mr. Letian X Xie for their help with the CoQ10 measurements.

1. Hanahan D, Weinberg RA. Hallmarks of cancer: the next generation. Cell 2011; 144: 646-674.

2. Gogvadze V, Orrenius S, Zhivotovsky B. Mitochondria as targets for chemotherapy. Apoptosis 2009; 14: 624-640.

3. Verfaillie T, Garg AD, Agostinis P. Targeting ER stress induced apoptosis and inflammation in cancer. Cancer Lett 2010; e-pub ahead of print 21 August 2010; doi:10.1016/j.canlet. 2010.07.016

4. Reddy ST, Devarajan A, Bourquard N, Shih D, Fogelman AM. Is it just paraoxonase 1 or are other members of the paraoxonase gene family implicated in atherosclerosis? Curr Opin Lipidol 2008; 19: 405-408.

5. Draganov DI, Teiber JF, Speelman A, Osawa Y, Sunahara R, La Du BN. Human paraoxonases (PON1, PON2, and PON3) are lactonases with overlapping and distinct substrate specificities. J Lipid Res 2005; 46: 1239-1247.

6. Teiber JF, Billecke SS, La Du BN, Draganov DI. Estrogen esters as substrates for human paraoxonases. Arch Biochem Biophys 2007; 461: 24-29.

7. Ng CJ, Shih DM, Hama SY, Villa N, Navab M, Reddy ST. The paraoxonase gene family and atherosclerosis. Free Radic Biol Med 2005; 38: 153-163.

8. Reddy ST, Wadleigh DJ, Grijalva V, Ng C, Hama S, Gangopadhyay A et al. Human paraoxonase-3 is an HDL-associated enzyme with biological activity similar to paraoxonase-1 protein but is not regulated by oxidized lipids. Arterioscler Thromb Vasc Biol 2001; 21: 542-547.

9. Bourquard N, Ng CJ, Reddy ST. Impaired hepatic insulin signalling in PON2-deficient mice: a novel role for the PON2/apoE axis on the macrophage inflammatory response. Biochem J 2011; 436: 91-100.

10. Yuan J, Devarajan A, Moya-Castro R, Zhang M, Evans S, Bourquard N et al. Putative innate immunity of antiatherogenic paraoxonase-2 via STAT5 signal transduction in HIV-1 infection of hematopoietic TF-1 cells and in SCID-hu mice. J Stem Cells 2010; 5: 43-48.

11. Ng CJ, Bourquard N, Grijalva V, Hama S, Shih DM, Navab M et al. Paraoxonase-2 deficiency aggravates atherosclerosis in mice despite lower apolipoprotein-B-containing lipoproteins: anti-atherogenic role for paraoxonase-2. J Biol Chem 2006; 281: 29491-29500.

12. Altenhofer S, Witte I, Teiber JF, Wilgenbus P, Pautz A, Li H et al. One enzyme, two functions: PON2 prevents mitochondrial superoxide formation and apoptosis independent from its lactonase activity. J Biol Chem 2010; 285: 24398-24403.

13. Devarajan A, Bourquard N, Hama S, Navab M, Grijalva V, Morvardi S et al. Paraoxonase 2 deficiency alters mitochondrial function and exacerbates the development of atherosclerosis. Antioxid Redox Signal 2011; 14: 341-351

14. Horke S, Witte I, Wilgenbus P, Kruger M, Strand D, Forstermann U. Paraoxonase-2 reduces oxidative stress in vascular cells and decreases endoplasmic reticulum stressinduced caspase activation. Circulation 2007; 115: 2055-2064.

15. Witte I, Altenhofer S, Wilgenbus P, Amort J, Clement AM, Pautz A et al. Beyond reduction of atherosclerosis: PON2 provides apoptosis resistance and stabilizes tumor cells. Cell Death Dis 2011; 2: e112.

16. Ross ME, Zhou X, Song G, Shurtleff SA, Girtman K, Williams WK et al. Classification of pediatric acute lymphoblastic leukemia by gene expression profiling. Blood 2003; 102: 2951-2959.

17. Kang H, Chen IM, Wilson CS, Bedrick EJ, Harvey RC, Atlas SR et al. Gene expression classifiers for relapse-free survival and minimal residual disease improve risk classification and outcome prediction in pediatric B-precursor acute lymphoblastic leukemia. Blood 2010; 115: $1394-1405$.

18. Frank $\mathrm{O}$, Brors B, Fabarius A, Li L, Haak M, Merk S et al. Gene expression signature of primary imatinib-resistant chronic myeloid leukemia patients. Leukemia 2006; 20: 1400-1407.

19. Schweikert EM, Amort J, Wilgenbus P, Foerstermann U, Teiber J, Horke S. Paraoxonases2 and 3 are important defense enzymes against Pseudomonas aeruginosa virulence factors due to their anti-oxidative and anti-inflammatory properties. J Lipids 2012 (in press).

20. Oyadomari S, Mori M. Roles of CHOP/GADD153 in endoplasmic reticulum stress. Cell Death Differ 2004; 11: 381-389.

21. Witte I, Horke S. Assessment of endoplasmic reticulum stress and the unfolded protein response in endothelial cells. Methods Enzymol 2011; 489: 127-146.

22. Draganov DI, Stetson PL, Watson CE, Billecke SS, La Du BN. Rabbit serum paraoxonase 3 (PON3) is a high density lipoprotein-associated lactonase and protects low density lipoprotein against oxidation. J Biol Chem 2000; 275: 33435-33442.

23. Kagan VE, Bayir HA, Belikova NA, Kapralov O, Tyurina YY, Tyurin VA et al. Cytochrome c/cardiolipin relations in mitochondria: a kiss of death. Free Radic Biol Med 2009; 46: 1439-1453.

24. Kim I, Xu W, Reed JC. Cell death and endoplasmic reticulum stress: disease relevance and therapeutic opportunities. Nat Rev Drug Discov 2008; 7: 1013-1030.

25. Shiner M, Fuhrman B, Aviram M. Paraoxonase 2 (PON2) expression is upregulated via a reduced-nicotinamide-adenine-dinucleotide-phosphate (NADPH)-oxidase-dependent 
mechanism during monocytes differentiation into macrophages. Free Radic Biol Med 2004; 37: 2052-2063.

26. Fuhrman B, Gantman A, Khateeb J, Volkova N, Horke S, Kiyan J et al. Urokinase activates macrophage PON2 gene transcription via the PI3K/ROS/MEK/SREBP-2 signalling cascade mediated by the PDGFR-beta. Cardiovasc Res 2009; 84: 145-154.

27. Rosenblat M, Draganov D, Watson CE, Bisgaier CL, La Du BN, Aviram M. Mouse macrophage paraoxonase 2 activity is increased whereas cellular paraoxonase 3 activity is decreased under oxidative stress. Arterioscler Thromb Vasc Biol 2003; 23: 468-474.

28. Rothem L, Hartman C, Dahan A, Lachter J, Eliakim R, Shamir R. Paraoxonases are associated with intestinal inflammatory diseases and intracellularly localized to the endoplasmic reticulum. Free Radic Biol Med 2007; 43: 730-739.

29. Precourt LP, Seidman E, Delvin E, Amre D, Deslandres C, Dominguez M et al. Comparative expression analysis reveals differences in the regulation of intestinal paraoxonase family members. Int J Biochem Cell Biol 2009; 41: 1628-1637.

30. Deakin SP, Bioletto S, Bochaton-Piallat ML, James RW. HDL-associated paraoxonase-1 can redistribute to cell membranes and influence sensitivity to oxidative stress. Free Radic Biol Med 2011; 50: 102-109.

31. Witte I, Foerstermann U, Devarajan A, Reddy S, Horke S. Protectors and traitors - the roles of PON2 and PON3 in atherosclerosis and cancer. $J$ Lipids 2012 (in press).

32. Shih DM, Xia YR, Wang XP, Wang SS, Bourquard N, Fogelman AM et al. Decreased obesity and atherosclerosis in human paraoxonase 3 transgenic mice. Circ Res 2007; 100: 1200-1207.
33. Horke S, Witte I, Wilgenbus P, Altenhofer S, Kruger M, Li H et al. Protective effect of paraoxonase-2 against endoplasmic reticulum stress-induced apoptosis is lost upon disturbance of calcium homoeostasis. Biochem J 2008; 416: 395-405.

34. Graham JM. Isolation of mitochondria from tissues and cells by differential centrifugation. Curr Protoc Cell Biol 2001 (Chapter 3): Unit 3.3.

35. Zhang J, Liem DA, Mueller M, Wang $\mathrm{Y}$, Zong $\mathrm{C}$, Deng $\mathrm{N}$ et al. Altered proteome biology of cardiac mitochondria under stress conditions. J Proteome Res 2008; 7: 2204-2214.

36. Pedersen PL, Greenawalt JW, Reynafarje B, Hullihen J, Decker GL, Soper JW et al Preparation and characterization of mitochondria and submitochondrial particles of rat liver and liver-derived tissues. Methods Cell Biol 1978; 20: 411-481.

37. Morten KJ, Ackrell BA, Melov S. Mitochondrial reactive oxygen species in mice lacking superoxide dismutase 2: attenuation via antioxidant treatment. J Biol Chem 2006; 281: 3354-3359.

38. Zmijewski JW, Lorne E, Banerjee S, Abraham E. Participation of mitochondrial respiratory complex III in neutrophil activation and lung injury. Am J Physiol Lung Cell Mol Physiol 2009; 296: L624-L634.

39. Muller F, Crofts AR, Kramer DM. Multiple Q-cycle bypass reactions at the Qo site of the cytochrome bc1 complex. Biochemistry 2002; 41: 7866-7874.

40. Marbois B, Xie LX, Choi S, Hirano K, Hyman K, Clarke CF. para-Aminobenzoic acid is a precursor in coenzyme Q6 biosynthesis in Saccharomyces cerevisiae. J Biol Chem 2010; 285: $27827-27838$.

Supplementary Information accompanies the paper on Cell Death and Differentiation website (http://www.nature.com/cdd) 